\title{
Endothelin content of bronchoalveolar lavage fluid from allotransplanted pigs is increased during unmodified rejection
}

To find a new method for detection of rejection of allotransplanted lungs, we studied the endothelin content of bronchoalveolar lavage fluid by radioimmunoassay. Left-sided lung allotransplantation was performed in pigs. One group of animals received no treatment with immunosuppressive drugs (rejection group), the other group of animals (treated group) was treated with a triple-drug immunosuppressive regimen (cyclosporine, azathioprine, and methylprednisone), and nontransplanted lungs were controls. The endothelin content in bronchoalveolar lavage fluid was significantly elevated in the group of pigs with unmodified rejection $(29.20 \pm 1.96 \mathrm{pg} / \mathrm{ml})$ compared with that in the immunosuppressed group $(15.3 \pm 2.4 \mathrm{pg} / \mathrm{ml})$ and control group $(4.27 \pm 1.23 \mathrm{pg} / \mathrm{ml})$. The measurements were made from 5,33 , and 11 samples of bronchoalveolar lavage fluid from the rejection, treated, and control groups, respectively. These results suggest that endothelin content of bronchoalveolar lavage fluid could be a marker of lung allograft rejection. (J THORAC CARDIOvaSC SURG 1994;107:216-9)

Pertti Aarnio, MD, Pekka Hämmäinen, MD, Frej Fyhrquist, MD, ${ }^{a}$ and Ari Harjula, MD, Helsinki, Finland

$\mathrm{L}$ transplantation in its various forms has become an option for patients with end-stage lung diseases. ${ }^{1-3}$ Although the results have improved, there still remain problems with infection, rejection, and, in the long term, bronchiolitis obliterans. The cornerstone for detection of rejection has been transbronchial biopsy. ${ }^{4}$ However, this invasive procedure is associated with serious complications such as bleeding, pneumothorax, and even death, although rarely.

Endothelin-1 is a potent vasoconstrictive agent produced by vascular endothelial cells. ${ }^{5}$ Cultured human bronchial smooth muscle cells have specific binding sites for endothelin, and bronchial epithelial cells secrete endothelin-like material. ${ }^{6}$ Bronchial epithelial cells

From the Departments of Thoracic and Cardiovascular Surgery and Internal Medicine, ${ }^{a}$ Helsinki University Central Hospital, Helsinki, Finland.

Received for publication March 12, 1993.

Accepted for publication July 7, 1993.

Address for reprints: Pertti Aarnio, MD, Department of Thoracic and Cardiovascular Surgery, Helsinki University Central Hospital, Haartmaninkatu 4, 00290 Helsinki, Finland.

Copyright $₫ 1994$ by Mosby-Year Book, Inc.

$0022-5223 / 94 \$ 1.00+.10 \quad \mathbf{1 2} / \mathbf{1} / \mathbf{5 0 4 7 8}$ express transplantation antigens and the rejection process may affect their secretion of endothelin-like substances. ${ }^{7}$ Therefore we decided to study the endothelin content in bronchoalveolar lavage (BAL) fluid from pigs receiving a single lung allotransplant to find a new method for detection of rejection.

\section{Materials and methods}

Left-sided single lung transplantations were done in piglets weighing 13 to $22 \mathrm{~kg}$. The size-matched donor lungs were pretreated with intravenous prostaglandin $E_{1}$ infusion and preserved with modified Euro-Collins solution. The contralateral pulmonary artery was reduced by about $30 \%$ from the original diameter by ligature to enhance the blood flow to the transplanted lung. A previously described operation on piglets was thereby slightly modified. ${ }^{8}$ All animals received humane care in compliance with the "Principles of Laboratory Animal Care" formulated by the National Society for Medical Research.

One group of piglets was treated with methylprednisone ( 1 $\mathrm{mg} / \mathrm{kg})$, cyclosporine $(15 \mathrm{mg} / \mathrm{kg})$, and azathioprine $(2 \mathrm{mg} / \mathrm{kg})$ daily perorally. Methylprednisone was given intravenously 30 $\mathrm{mg} / \mathrm{kg}$ intraoperatively, and a 3-day course of $500 \mathrm{mg}$ methylprednisone intramuscularly was given in case of acute rejection (treated group). The other group of piglets did not receive any immunosuppression (rejection group). All animals received ampicillin $1 \mathrm{gm} /$ day perorally for 1 week or as long as atelectasis existed.

Piglets were examined on days $3,5,7,10,14,22$, and 30 after 


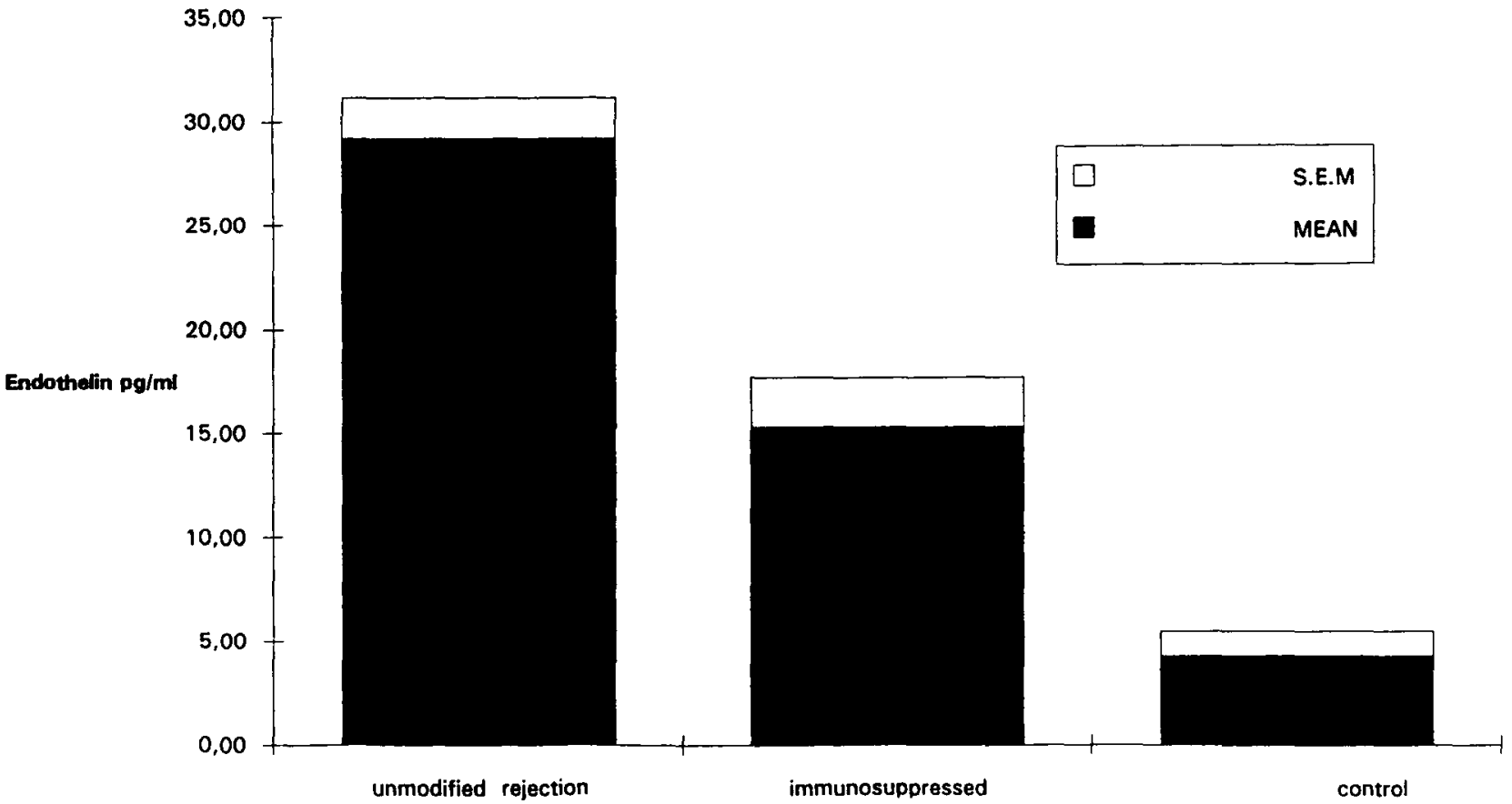

Fig. 1. Endothelin content of BAL fluid. Content of endothelin in unmodified rejection group was significantly higher $(p<0.01)$ than that in immunosuppressed group. Control samples had significantly lower levels of endothelin ( $p<0.001$ ) than other groups. SEM, Standard error of the mean.

operation and at least monthly up to 134 days. In addition to BAL, computed tomography, plain chest films, and transtho$\mathrm{racic} /$ transbronchial biopsies were done with the use of general anesthesia. The BAL samples from purulent infection foci of the lung or from local radiologically infectious infiltration of the lung were excluded in this study. The BAL fluid samples were stored at $-20^{\circ} \mathrm{C}$ until studied for endothelin content by a radioimmunoassay, the method of which has been previously described. ${ }^{9}$ The BAL fluid from unoperated pig lungs served as controls. The antiserum used in the radioimmunoassay showed less than $0.1 \%$ cross-reaction with big endothelin- 11 to 38 and 22 to 38 fragments, the 20 to 50,74 to 91 , and 171 to 201 sequences of preproendothelin-1, atrial natriuretic peptide, angiotensin II, and $\mathrm{Arg}^{8}$-vasopressin. It cross-reacted $100 \%$ with endothelin-2 and endothelin-3. Further details are given elsewhere. ${ }^{9}$

The results are expressed as the means plus or minus the standard error of the mean. Analysis of variance was used to compare means among the groups. When a significant $F$ value was found, Sheffe's test was used to identify differences among means. Values were considered to be statistically significantly different when $p<0.05$.

\section{Results}

The pigs receiving triple-drug immunosuppressive therapy survived for between 3 and 134 days. Altogether 33 adequate BAL fluid samples were collected from these animals. The histologic studies showed that alveolar structure was always well preserved in the biopsy material. The reimplantation responses of the seven allotransplanted lungs were seen as centrally located infiltrates at day 3 , and the infiltrates disappeared in 10 days. These infiltrates were different from those observed in the unmodified rejection group at the same time. The radiologic changes in rejection were diffuse throughout the whole lung. In four animals the rejection was suspected radiologically and confirmed by histologic examination, which showed mild rejection in three cases. Only one pig had very mild rejection noticed in histologic samples taken at autopsy without any clinical or radiologic findings, but some transbronchial biopsy samples were not presentative enough to exclude mild rejection. Five BAL samples were taken from three pigs with unmodified rejection. These animals lived 4 to 22 days (mean 10 days). In the histologic samples changes varied from nonspecific reactions to perivascular and peribronchiolar mononuclear cell infiltrations. These changes led to destruction of the general alveolar structure after the second postoperative week.

The endothelin content in BAL fluid was $15.30 \pm 2.41$ $\mathrm{pg} / \mathrm{ml}$ in the group treated with triple-drug immunosuppression and $29.20 \pm 1.96 \mathrm{pg} / \mathrm{ml}$ in the unmodified rejection group ( $p<0.01$; Fig. 1$)$. The control BAL 
samples from unoperated lungs $(n=11)$ had a significantly lower content of endothelin, $4.27 \pm 1.23 \mathrm{pg} / \mathrm{ml}$, compared with that in the other groups $(p<0.001)$.

\section{Discussion}

Interestingly we found that the endothelin content in BAL fluid is increased during unmodified lung allograft rejection compared with the endothelin content in immunosuppressed animals. Small amounts of endothelin were detected also in BAL fluid from unoperated lungs. The source of immunoreactive endothelin in BAL fluid was not identified in this study.

Endothelin content in BAL fluid has been observed to increase also in patients with bronchial asthma at the time they are having symptoms. ${ }^{10}$ The endothelin content in BAL fluid was fourfold higher in patients with symptomatic asthma compared with the level in control subjects. In our study the endothelin content in BAL fluid increased threefold in treated animals with allografts and sevenfold in animals with unmodified rejection. The same authors have demonstrated that human bronchial muscle cells possess a single class of specific binding sites for endothelin- $1{ }^{6}$ The receptor for endothelin on human bronchial smooth muscle has been isolated and provided circumstantial evidence that it belongs to the protein G-coupled receptor superfamily. ${ }^{11}$ The effect of endothelin in the bronchial smooth muscle is contraction, as it is in arteries and veins. In particular, endothelin-1 represents the most potent constrictor of guinea pig tracheal and human bronchial smooth muscle. ${ }^{12-14}$ The activity of endothelin-1 appears to involve the action of voltage-dependent calcium channels at low concentrations, whereas a direct effect of this peptide on intracellular calcium, via the activation of phosphatidylinositol hydrolysis, and on protein kinase $\mathrm{C}$ may be involved in smooth muscle contraction induced by concentrations of endothelin-1 greater than $10^{-8} \mathrm{~mol} / \mathrm{L} .^{11,14}$

The pathophysiologic constrictor effect of endothelin in bronchus is not clear; at least that bronchoconstriction observed in asthma is harmful. Obviously the increased endothelin content in BAL fluid of transplanted lung allografts causes bronchoconstriction thus impairing the ventilation and the drainage of secretions from the lungs. The accumulation of secretions in the lungs is an important clinical problem in patients with lung transplant, because the function of the cilia of the bronchial epithelium is impaired, too. The chronic effect of the high concentrations of endothelin may be considered in another important problem with lung transplantations, namely, bronchiolitis obliterans, the cause of which is not known yet.

It has been suggested that the main source of endothe- lin production is from the bronchial epithelium because of reported production of high amounts of endothelin-1-like material by human bronchial epithelial cells in vitro under conditions that cause continuous injury and repair of cells. ${ }^{6}$ The other evidence for this is the observation that the increase of endothelin in BAL fluid from the patients with asthma is disproportionate for the albumin levels and is not associated with a parallel increase in the amounts of circulating endothelin. ${ }^{10}$ The other possible sources of endothelin in bronchial fluid are the endothelium of the vasculature near bronchi and the immunologically active cells around bronchi caused by the rejection process or the circulating cells activated in infection and inflammation. Polymorphonuclear cells and lymphocytes are increased in number and the alveolar macrophages are proportionally decreased in lavage fluid during lung allograft rejection. ${ }^{15}$ Human alveolar macrophages synthesize and release endothelins, but neutrophils and lymphocytes cannot. ${ }^{16}$

It has also been shown that cyclosporine increases the production of endothelin in renal tissues of rats and causes an upregulation of renal endothelin receptors. ${ }^{17,}{ }^{18}$ The threefold increase of endothelin content in BAL fluid from the group of piglets treated in our study with cyclosporine was probably partly a result of the known induction of endothelin synthesis by cyclosporine, ${ }^{17}$ but could also be a result of factors associated with transplantation per se or with methylprednisolone treatment. The further twofold increase of endothelin in BAL fluid in the rejection group was quite marked, inasmuch as these animals did not receive cyclosporine treatment.

\section{REFEREN C ES}

1. Pearson FG. Lung transplantation: the Toronto experience. Eur J Cardiothorac Surg 1989;3:6-11.

2. McGregor CGA, Jamieson SW, Baldwin JC, et al. Combined heart-lung transplantation for end-stage Eisenmenger's syndrome. J THORAC CARDIOvaSC SuRg 1986; 91:443-550.

3. Griffith BP, Hardesty RL, Trento A, et al. Heart-lung transplantation: lessons learned and future hopes. Ann Thorac Surg 1987;43:6-16.

4. Yousem SA, Berry GJ, Brunt EM, et al. A working formulation for the standardization of nomenclature in the diagnosis of heart and lung rejection: lung rejection study group. J Heart Transplant 1990;9:593-601.

5. Yanagisawa M, Kurihara H, Kimura S. A novel potent vasoconstrictor peptide produced by vascular endothelial cells. Nature 1988;332:41 1-5.

6. Mattoli S, Mezzetti M, Riva G, Allegra L, Fasoli A. Specific binding of endothelin on human bronchial smooth muscle cells in culture and secretion of endothelin-like 
material from bronchial epithelial cells. Am J Respir Cell Mol Biol 1990;3:145-51.

7. Romaniuk A, Prop J, Petersen AH, Wildevuur RH, Nieuwenhuis P. Expression of class II major histocompatibility complex antigens by bronchial epithelium in rat lung allografts. Transplantation 1987;44:209-14.

8. Harjula ALJ, Baldwin JC. Lung transplantation in the pig with successful preservation using prostaglandin E-1. J Appl Cardiol 1987;2:397-402.

9. Fyhrquist F, Saijonmaa O, Metsärinne K, et al. Raised plasma endothelin-l concentration following cold pressor test. Biochem Biophys Res Commun 1990;169:217-21.

10. Mattoli S, Soloperto M, Marini M, Fasoli A. Levels of endothelin in bronchoalveolar lavage fluid of patients with symptomatic asthma and reversible airflow obstruction. $\mathbf{J}$ Allergy Clin Immunol 1991;88:376-84.

11. Marini M, Mezzetti M, Fasoli A, Mattoli S. Mechanisms of calcium mobilization and phosphoinositide hydrolysis in human bronchial smooth muscle cells by endothelin 1. Am J Respir Cell Mol Biol 1991;5:424-30.

12. Uchida $Y$, Ninomiya H, Saotome M. Endothelin, a novel vasoconstrictor peptide, as potent bronchoconstrictor. Eur J Pharmacol 1988;154:227-9.

13. Lagente V, Chabrier PE, Mencia-Huerta JM, Braquet P.
Pharmacological modulation of the bronchopulmonary action of the vasoactive peptide endothelin, administered by aerosol in the guinea pig. Biochem Biophys Res Commun 1989;158:625-32.

14. Advenier C, Sarria B, Naline E, Bybasset L, Lagente V. Contractile activity of three endothelins (ET-1, ET-2, and ET-3) on the human isolated bronchus. $\mathrm{Br} \mathrm{J}$ Pharmacol 1990;100:168-72.

15. Fiehl E, Hoefter E, Krombach F, et al. Hetero-orthotopic heart-lung transplantation in the dog: bronchoalveolar lavage versus histologic findings. Transplant Proc 1988;20: 668-9.

16. Ehrenreich $\mathrm{H}$, Anderson RW, Fox CH, et al. Endothelins, peptides with potent vasoactive properties, are produced by human macrophages. J Exp Med 1990;172:1741-8.

17. Brooks DP, Ohlstein EH, Contino LC, et al. Effect of nifedipine on cyclosporine A-induced nephrotoxicity, urinary endothelin excretion and renal endothelin receptor number. Eur J Pharmacol 1991;194:115-7.

18. Nambi P, Pullen M, Contino LC, Brooks DP. Upregulation of renal endothelin receptors in rats with cyclosporine A-induced nephrotoxicity. Eur J Pharmacol 1990;187: 113-6. 